Disponível em

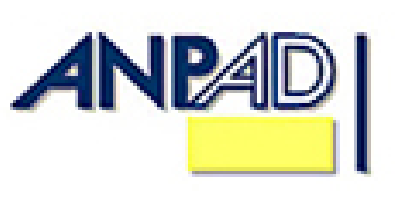

http://www.anpad.org.br/rac

RAC, Rio de Janeiro, v. 19, Edição Especial, art. 3, pp. 38-52, Maio 2015

http://dx.doi.org/10.1590/1982-7849rac2015140097

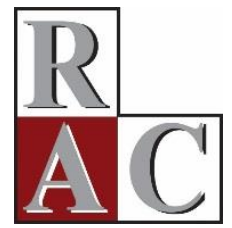

$($ co) EY-NG

\title{
Relevância de Prêmio por Risco País no Custo de Capital das Empresas
}

Relevance of Country Risk Premium in Cost of Equity Estimation

Antonio Zoratto Sanvicente

Fundação Getulio Vargas - FGV 


\title{
Resumo
}

A prática comum nos procedimentos de avaliação de empresas e na fixação de taxas de retorno por agências regulatórias é usar o capital asset pricing model (CAPM) com a adição de um prêmio por risco Brasil. O presente trabalho documenta essa prática nos laudos de avaliação de empresas para fins de oferta pública de aquisição (OPA), disponíveis no site da Comissão de Valores Mobiliários, e utiliza o método de regressão linear múltipla com retornos mensais de 204 empresas com ações negociadas na BM\&FBovespa, cobrindo o período de janeiro de 2009 a dezembro de 2013. A análise conclui que em apenas 17 títulos, o prêmio por risco Brasil não está completamente refletido no comportamento do Ibovespa. Assim, caso seja usado o índice de mercado local para a finalidade de estimação do custo de capital próprio de uma empresa, é redundante e incorreto acrescentar o prêmio por risco Brasil. O trabalho conclui com um exemplo de aplicação do enfoque usual e do enfoque resultante desta constatação a uma empresa real, e aponta que pode haver um erro de precificação correspondente a aproximadamente $17 \%$.

Palavras-chave: risco Brasil; custo de capital próprio; avaliação de ações; taxas justas de retorno.

\begin{abstract}
A common practice in business valuation and the determination of fair rates of return by regulatory agencies is to use the capital asset pricing model (CAPM) with the ad hoc addition of a country risk premium. The present paper documents this practice in the valuation reports required in public acquisition offers available on the CVM (Brazilian Securities and Exchange Commission) website. Multiple linear regression is used with monthly returns for stock shares of 204 firms listed on the BM\&FBovespa (Brazilian Stock Exchange). The period covered is from January 2009 to December 2013, and the results indicate that there is a premium for Brazilian risk that is not completely reflected in Ibovespa returns for only 17 securities. Hence, if one uses the local market index when estimating a firm's cost of equity, it would be both redundant and incorrect to add a country risk premium. The paper concludes with a real company example in which the adoption of the conventional approach - with a country risk premium added - would lead to a $17 \%$ pricing error.
\end{abstract}

Key words: country risk premium; cost of equity; stock valuation; fair rates of return. 


\section{Introdução}

A estimação do custo de capital próprio das empresas, utilizado como componente do custo médio de capital (WACC), possui pelo menos duas aplicações práticas frequentes e bastante importantes: (a) como taxa de desconto em processos de avaliação e (b) como taxa justa regulatória de retorno em esquemas de concessão de serviços de utilidade pública.

Em tais aplicações, é prática generalizada a inclusão de um prêmio por risco país, representando basicamente o retorno adicional que um investidor exigiria, em acréscimo à taxa de retorno livre de risco no mercado internacional, em um investimento que ocorre em algum setor da economia brasileira.

Neste documento, descrevemos essa prática nos dois âmbitos mencionados acima. No caso de processos de avaliação, focalizamos a atenção nos laudos elaborados pelas principais empresas de consultoria para a determinação de preços de ações em ofertas públicas de aquisição (OPAs) visando ao fechamento de empresas abertas. No caso de taxas regulatórias, fazemos referência explícita à prática e ao raciocínio de duas agências regulatórias importantes, a saber, a Agência Nacional de Energia Elétrica (ANEEL) e a Agência Nacional de Transportes Terrestres (ANTT).

De maneira resumida, essas aplicações incluem o prêmio por risco país no cálculo do que chamam de capital asset pricing model (CAPM), e o fazem, com frequência, a partir de uma série histórica de prêmios observados. O presente documento mostrará que (a) a inclusão de prêmio por risco país é irrelevante e desnecessária, ao se medir o prêmio por risco de mercado com o índice de mercado de ações do próprio país, e que (b) a utilização de prêmios históricos, de qualquer natureza, é incoerente em relação aos princípios básicos de finanças.

Após esta Introdução, é feita uma revisão do modelo básico utilizado (CAPM). A seguir, é feito um relato do que é incorporado pelos laudos de avaliação para OPAs nas taxas de desconto necessárias. É feita subsequentemente uma descrição dos procedimentos de inclusão de prêmio por risco país segundo as notas técnicas emitidas pelas duas agências regulatórias acima mencionadas. Logo em seguida é discutida a validade de medir prêmios por qualquer tipo de risco em termos históricos e demonstrada a alternativa mais apropriada, que consiste em utilizar cotações correntes e disponíveis no mercado. No item seguinte é demonstrada empiricamente, com dados de 204 ações negociadas na BM\&FBovespa, a irrelevância do prêmio por risco país quando o risco de mercado é medido com a carteira de mercado local de ações, mesmo que o risco país não seja expresso em termos históricos, e sim correntes. Essa demonstração é seguida por um exemplo contrastando a metodologia mais apropriada (prêmio por risco de mercado apenas, medido em termos correntes) com a metodologia preconizada por uma das agências regulatórias, para que se tenha uma ideia tangível do viés provocado pelo uso de enfoques incorretos.

\section{Aplicação do CAPM: Questões Gerais}

Em sua versão inicial, atribuída a Sharpe (1964), Lintner (1965) e Mossin (1966), o capital asset pricing model (CAPM) é amplamente utilizado hoje em dia em processos de estimação de taxas de desconto para a avaliação de empresas. Algumas aplicações de destaque incluem as privatizações ocorridas no Brasil, a emissão de ofertas públicas de aquisição (OPAs) para fechamento de companhias abertas, a implantação de sistemas de avaliação de desempenho de unidades de negócios e executivos com base no cálculo de $\mathrm{EVA}^{\circledR}$ (ver, por exemplo, Stewart, 1991), e os estudos destinados a revisões tarifárias de empresas concessionárias sob regulamentação econômica (ver, por exemplo, http://www.aneel.gov.br), para citar apenas quatro áreas de aplicação importantes. Em todos os casos, um dos principais resultados do CAPM, a chamada equação da security market line, é empregado como modelo de determinação de uma taxa de retorno exigida, ou seja, uma taxa de desconto de fluxos de caixa projetados. Nos laudos de avaliação em OPAs, isso é explicitado como sendo a aplicação do método de fluxo de caixa descontado. 
Como se sabe, a equação da security market line diz que o retorno exigido de qualquer ativo é igual à taxa de retorno (juros) livre de risco, mais um prêmio por risco não diversificável. Este último prêmio, por sua vez, resulta da multiplicação entre o excedente esperado de retorno da carteira de mercado e o grau de risco não diversificável desse ativo, ou seja, o beta do ativo.

Portanto, o modelo diz que há apenas um fator de risco, proporcional à quantidade de risco não diversificável do ativo, e esse fator é o risco da carteira de mercado. Em outras palavras, não está prevista a inclusão de prêmio por qualquer outro tipo de risco. Do ponto de vista da utilização dessa versão do CAPM, a adição de prêmio por outro risco que não o da carteira de mercado consiste em um procedimento inteiramente ad hoc.

Entretanto, em um estudo apoiado na aplicação de questionários respondidos por ex-alunos de uma das principais escolas de Administração dos Estados Unidos, Keck, Levengood e Longfield (1998) constataram que a utilização do CAPM na estimação de taxas de desconto padece de um defeito evidente, qual seja, o uso ad hoc de prêmios por risco, não previstos no CAPM, e não necessariamente validados do ponto de vista empírico. Um exemplo frequente disso é o prêmio por risco soberano (risco país).

\section{Levantamento da Prática de Utilização do Método de Fluxos de Caixa Descontados em Laudos de Avaliação para Ofertas Públicas de Aquisição de Ações (OPAs)}

Como evidência da utilização prática do CAPM no Brasil numa das áreas já mencionadas, foi feito um levantamento nos laudos de avaliação, disponíveis no site da Comissão de Valores Mobiliários (http://www.cvm.gov.br), abrangendo ofertas públicas de aquisição registradas no período de 2008 a 2013. Sessenta e nove laudos foram encontrados, com 52 deles envolvendo a escolha do método de fluxo de caixa descontado para fins de estimação do preço de oferta pública de aquisição.

Inicialmente, consideramos de que maneira foram escolhidos os valores para a taxa de retorno livre de risco e para o prêmio por risco de mercado.

Quanto à taxa de retorno livre de risco, sem exceção, os consultores utilizaram a taxa de juros de títulos de longo prazo do Tesouro dos Estados Unidos. Entretanto, embora estivéssemos sempre tratando de avaliação de ações, ou seja, títulos cujo prazo de vencimento é indeterminadamente longo, os horizontes escolhidos foram bem diversos, como mostra a Tabela 1.

Tabela 1

Títulos do Tesouro dos Estados Unidos Utilizados como Proxy de Ativo Livre de Risco em Laudos de Avaliação para Ofertas Públicas de Aquisição, 2008-2013

\begin{tabular}{lc}
\hline Título & Frequência (número de ocorrências) \\
\hline US Treasury Notes -10 anos (UST10) & 22 \\
US Treasury Notes -20 anos (UST20) & 02 \\
US Treasury Notes -30 anos (UST30) & 26 \\
Sem informação & 02 \\
\hline
\end{tabular}

Nota. Comissão de Valores Mobiliários. (2008). Laudos e editais de OPAs registradas em 2008. Recuperado de http://sistemas.cvm.gov.br/?OfertasReg; Comissão de Valores Mobiliários. (2009). Laudos e editais de OPAs registradas em 2009. Recuperado de http://sistemas.cvm.gov.br/?OfertasReg; Comissão de Valores Mobiliários. (2010). Laudos e editais de OPAs registradas em 2010. Recuperado de http://sistemas.cvm.gov.br/?OfertasReg; Comissão de Valores Mobiliários. (2011). Laudos e editais de OPAs registradas em 2011. Recuperado de http://sistemas.cvm.gov.br/?OfertasReg; Comissão de Valores Mobiliários. (2012). Laudos e editais de OPAs registradas em 2012. Recuperado de http://sistemas.cvm.gov.br/?OfertasReg; Comissão de Valores Mobiliários. (2013). Laudos e editais de OPAs registradas em 2013. Recuperado de http://sistemas.cvm.gov.br/?OfertasReg 
A lamentar, porém, que em dois casos o laudo sequer especificou que ativo desempenhou o papel de título sem risco na avaliação.

Chama mais atenção, porém, a dispersão com a qual as várias firmas de consultoria escolhem usar taxas correntes de mercado em contraste com taxas históricas. Neste último caso, o que se quer dizer é que foi tirada uma média simples de valores passados de taxas do título escolhido.

Como se trata de um mercado com elevadíssima liquidez e, portanto, com participação efetiva de um grande número de investidores, espera-se que esse mercado seja razoavelmente eficiente e que cotações correntes sejam perfeitamente representativas de um custo de oportunidade livre de risco. Uma das consultorias, em laudo de avaliação de 2010, defende a escolha do enfoque média histórica da seguinte maneira: "Entendemos que a média dos 24 meses diminui os efeitos de variações diárias da taxa e, por conseguinte, melhor reflete o retorno esperado destes títulos no longo prazo" (Deloitte Touche Tohmatsu, 2009). Ou seja, o retorno esperado para o futuro é uma média simples dos retornos ocorridos no passado. Neste caso específico, o passado é o período de 24 meses anteriores.

A Tabela 2 informa as frequências com as quais taxas correntes e taxas médias históricas foram utilizadas.

Tabela 2

Estimação da Taxa de Retorno Livre de Risco: Valores Correntes Versus Médias Históricas em Laudos de Avaliação para Ofertas Públicas de Aquisição, 2008-2013

\begin{tabular}{lc}
\hline Forma de cálculo & Frequência (número de ocorrências) \\
\hline Taxa corrente de mercado & 11 \\
Taxa média histórica & 35 \\
Sem informação & 06 \\
\hline
\end{tabular}

Nota. Comissão de Valores Mobiliários. (2008). Laudos e editais de OPAs registradas em 2008. Recuperado de http://sistemas.cvm.gov.br/?OfertasReg; Comissão de Valores Mobiliários. (2009). Laudos e editais de OPAs registradas em 2009. Recuperado de http://sistemas.cvm.gov.br/?OfertasReg; Comissão de Valores Mobiliários. (2010). Laudos e editais de OPAs registradas em 2010. Recuperado de http://sistemas.cvm.gov.br/?OfertasReg; Comissão de Valores Mobiliários. (2011). Laudos e editais de OPAs registradas em 2011. Recuperado de http://sistemas.cvm.gov.br/?OfertasReg; Comissão de Valores Mobiliários. (2012). Laudos e editais de OPAs registradas em 2012. Recuperado de http://sistemas.cvm.gov.br/?OfertasReg; Comissão de Valores Mobiliários. (2013). Laudos e editais de OPAs registradas em 2013. Recuperado de http://sistemas.cvm.gov.br/?OfertasReg

No caso da opção por médias históricas, também foi observada grande variabilidade: em sete casos não foi fornecida informação quanto aos prazos utilizados. Quando essa informação foi fornecida, os dois prazos mais frequentemente observados foram: 12 meses (8); 3 meses (7); 24 meses (6). Há também opções por uma semana, de um lado, e por 80 anos, de outro.

Vê-se, assim, que a prática é predominantemente baseada em médias de taxas passadas, o que não condiz com a lógica e com os fundamentos da teoria básica de finanças, e assim mesmo essa prática é muito variável.

Pior ainda, porém, é a situação quando se verifica o que é feito com a estimação do prêmio por risco de mercado.

Em primeiro lugar, não é muito claro o que fazem de fato os consultores, pois há dúvidas sobre o uso explícito de alguma carteira correspondente a algum índice conhecido - como o S\&P500. Muitos laudos referem-se a carteiras diversificadas de ações de grandes empresas norte-americanas, outros a Ibbotson, ou seja, algum índice resultante do trabalho originalmente desenvolvido no Center for Research in Securities Prices (CRSP), mas sem se saber qual índice de Ibbotson. A crítica natural, evidentemente, é a dificuldade para a replicação do que os consultores fizeram em seus laudos. 
Tal como no caso da taxa livre de risco, há o problema conceitual básico decorrente da utilização de médias históricas. Três laudos mencionam o uso do método de Damodaran, em referência ao professor Aswath Damodaran, da New York University. Em seu site (http://pages.stern.nyu.edu/ adamodar/), Damodaran publica tanto retornos esperados da carteira do mercado norte-americano sob a forma de média histórica quanto sob a forma implícita em preços correntes de ações e projeções de analistas.

Dentre os laudos que não se referem ao método de Damodaran, 30 explicitamente dizem que foram usadas médias históricas. Além desses casos, há uma avaliação baseada em prêmio projetado, mas não se sabe como é feita a projeção em outro caso, a avaliação é baseada em prêmio estimado, e também não se sabe como. Além destes, há cinco laudos sem qualquer informação a respeito de que índice foi usado para representar o mercado, e menos ainda sobre como o prêmio por risco de mercado foi estimado.

Novamente, tal como no caso da taxa de retorno livre de risco, observa-se grande variabilidade em termos de prazos utilizados para a estimação de médias históricas, indo desde 80 anos (12 casos), até apenas 4 anos, ou mesmo 110 anos. No caso dos 80 anos, trata-se de uma aproximação que estamos fazendo da informação de que a série começa em 1926, no mercado norte-americano. No entanto, isso pode ser idêntico a dizer que são usados os cálculos de Ibbotson. Enfim, a informação sobre dimensão tão importante de uma avaliação é bastante confusa, dificultando sobremaneira a replicação do que foi feito pelos consultores.

Por fim, destaca-se o argumento utilizado num dos laudos de 2008, a respeito do uso como referência de uma carteira de mercado de ações de outro país:

Neste contexto, o prêmio de risco de mercado é calculado através da regressão entre a rentabilidade do mercado acionário e a rentabilidade de instrumentos de dívida pública. Dada a reduzida liquidez e falta de dados históricos do mercado brasileiro, a prática adotada é de se usar dados do mercado norte-americano. (Hirashima \& Associados, 2008, p. 20).

Ou seja, muitos consultores não confiam ainda na maturidade do mercado brasileiro de ações como fonte de informação para a precificação de riscos relevantes. No trecho citado, além disso, é incompreensível a referência à regressão entre taxas de retorno de carteira de ações e taxas de retorno de títulos públicos. É dito naquele laudo, ainda, que o professor Damodaran usaria o referido enfoque, o que claramente não é correto, caso seja feita uma leitura atenta de como ele realmente trabalha.

\section{Aplicação do CAPM com Prêmio por Risco País em Laudos de Avaliação}

Na totalidade dos 52 laudos analisados, as consultorias ajustaram o prêmio por risco de mercado por um prêmio por risco país. Parece óbvio que o raciocínio é o seguinte: como não acreditamos em prêmio por risco de mercado medido com a carteira local, usamos a carteira de um mercado internacional maduro, conforme trecho citado dois parágrafos acima. E o investidor - seja ele estrangeiro ou nacional - exigiria um prêmio pelo risco de fazer investimentos num mercado emergente, como o do Brasil. Para nós, a premissa é incorreta e, consequentemente, esse tipo de ajuste é desnecessário e pode gerar estimativas de taxas de desconto inadequadas para fins de uma avaliação de ações.

Mesmo assim, a variedade de tratamentos dados ao prêmio por risco país é impressionante.

Deve ser lembrado que, como o referido prêmio seria dado pela diferença entre a taxa de retorno de um título brasileiro e a de um título norte-americano, temos a escolha de índice ou taxa de referência. Em muitos casos, essa escolha é feita explicitamente pelo blended spread do EMBI+, índice calculado pelo banco J. P. Morgan (28 casos, dos quais 10 são baseados em taxas correntes, e 18, em médias de taxas históricas; estas últimas foram calculadas com prazos variando de um a 24 meses, sendo mais frequente o prazo de 12 meses). 
Em outros 17 casos menciona-se expressamente o uso de taxa de juros de títulos do Tesouro dos Estados Unidos (10, 20, ou 30 anos). Em apenas três desses casos é usada a diferença corrente entre taxas da dívida brasileira e do título norte-americano escolhido. E muitas vezes não é explicitado o título brasileiro empregado.

Por fim, para enfraquecer a possibilidade de replicação, em sete laudos não há informação sobre como o cálculo foi feito. Não ajuda muito a informação de que foi feito pelo Financial Strategies Group do Credit Suisse. Também é inusitada a informação de que o cálculo foi feito com o quociente entre o desvio-padrão do Ibovespa e o desvio-padrão do Global 40; afinal, prêmio por risco, ainda mais quando somado a taxas devidas a outros fatores de risco, deve ter unidades iguais às de uma taxa (\% ao ano, por exemplo), mas o quociente entre dois desvios-padrão é simplesmente um número sem qualquer tipo de unidade.

\section{Aplicação do CAPM com Prêmio por Risco País pelas Agências Regulatórias}

O trecho a seguir descreve resumidamente as metodologias de estimação de custo de capital próprio empregadas por duas importantes agências regulatórias federais: a Agência Nacional de Energia Elétrica (ANEEL) e a Agência Nacional de Transportes Terrestres (ANTT), de acordo com as notas técnicas mais recentes, disponíveis em seus sites.

No caso da ANEEL, o documento mais recente disponível é a Nota Técnica n. 75, com data de 22 de março de 2013.

De acordo com a Nota Técnica n. 75 (2013), fazem parte da estimação do custo de capital próprio: taxa livre de risco, prêmio por risco de mercado e prêmio por risco país. A taxa de retorno livre de risco é obtida calculando-se a média histórica de taxas cotadas mensalmente para obrigações do Tesouro dos Estados Unidos, com prazo de 10 anos, ao longo de um período de 17 anos (1995 a 2012, neste caso).

No que se refere ao prêmio por risco de mercado, também foi usada a média histórica da diferença entre retornos no mercado de ações dos Estados Unidos, representado pelo índice S\&P500 e as taxas de Treasury Bonds de 10 anos. Essa média foi calculada ao longo do período, desde 1928 até 2012 (84 anos, portanto).

Por fim, acrescenta-se o prêmio por risco país, cujo valor estimado é obtido com a mediana dos valores mensais para o spread de risco medido no índice EMBI+BR, ao longo do prazo de janeiro de 2000 a dezembro de 2012 (13 anos, portanto).

Ou seja, para a ANEEL, taxas médias passadas são representativas do que é justo remunerar num investimento de longo prazo no setor que regula, apesar da discussão feita na fl. 15 , a respeito da maior relevância de se usar "expectativas dos investidores quanto ao custo de capital" (Nota Técnica n. 75, 2013, fls. 15).

Em primeiro lugar, falar em expectativas de custo de capital é usar terminologia incorreta. Quando os investidores tomam suas decisões de inversão, eles consideram qual é o custo de oportunidade do capital, em vista das condições correntes de mercado, ou seja, o custo de capital corrente, e não o esperado para o futuro. E, como já foi demonstrado em outras publicações, inclusive as de Aswath Damodaran, muito citado nessa Nota Técnica, é possível sim, extrair o custo de oportunidade do capital em preços correntes de mercado, que correspondem, como seria de se esperar, aos valores descontados de fluxos de caixa futuros, estes sim, esperados pelos investidores. Ou seja, os preços nos dizem a que taxa exigida de retorno os investidores estão descontando os fluxos de caixa futuros esperados. 
Por causa desse desconhecimento técnico, a ANEEL considera "que a evidência histórica recente é um estimador adequado para estimar as taxas futuras, evitando a maior subjetividade inerente ao trabalho de fazer projeções para cada componente de risco" (Nota Técnica n. 75, 2013, fls. 16).

Ora, não só não é o caso de se fazer projeções de componentes de risco, como a história recente (mais de 10 anos, inclusive com uma grave crise em 2008) também não é evidência adequada para fins de estimação. Novamente, vemos aqui a premissa incorreta de que retornos médios passados são boa estimativa de retornos futuros.

Além de sua superioridade conceitual, o uso de prêmios por risco implícitos em preços correntes é superior em termos empíricos. Por exemplo, Carvalho e Sanvicente (2013), utilizando dados mensais de janeiro de 1995 a junho de 2012 e tendo estimado o prêmio por risco da carteira de mercado local com o enfoque de dividendos descontados, testam com a associação da variação desse prêmio as métricas convencionais de precificação de ativos e risco, tais como: taxa de juros de CDI, prêmio por risco Brasil e prêmio por liquidez do mercado norte-americano. Não apenas as variáveis são significantes, como a associação entre variações do prêmio por risco e das métricas de preço e risco é direta, como seria esperado. Exercício idêntico usando prêmios por risco baseados em retornos médios passados não produziu associação alguma com métricas de mercado como as citadas acima, ou quaisquer outras.

E, por fim, novamente aparece a crítica convencional e repetitiva ao uso de dados do mercado local de capitais:

É certo que do ponto de vista da consistência conceitual, o ideal seria estimar um CAPM local, determinando a taxa livre de risco, o prêmio de mercado e o beta sobre o mercado acionário local. Entretanto, em geral isto não é possível devido, entre outros, aos seguintes aspectos:

i. a qualidade e quantidade das informações disponíveis não o permitem, especialmente as relacionadas às empresas de transmissão de energia elétrica;

ii. os mercados de capitais não são amadurecidos e a diversificação de ativos é limitada;

iii. as séries de tempo não são suficientemente extensas;

iv. os fortes desequilíbrios macroeconômicos geram altas volatilidades dos ativos;

v. tem-se baixa liquidez em muitos casos, etc. (Nota Técnica n. 75, 2013, fls. 6).

Para a estimação da equação da security market line, ou seja, usar o CAPM, não importa o setor para o qual estamos fazendo uma avaliação. Somente o coeficiente beta depende disso. Portanto, o argumento i não é correto. Quanto ao argumento ii, quanto a ANEEL acha que devemos aguardar para decretar que o nosso mercado de capitais é suficientemente maduro? No argumento iii, basta mencionar que o uso de dados históricos em setores regulados nos Estados Unidos já ocorria na década de 1960, quando as séries disponíveis tinham pouco mais de 30 anos; como se sabe, nosso principal índice de mercado acionário já tem 45 anos de história. Qual é o mercado acionário que não tem volatilidade (argumento iv)? Para o argumento v, se liquidez for relevante, ela será precificada.

Em resumo, a metodologia da ANEEL opta por metodologia conceitualmente inconsistente por força de sua facilidade maior de aplicação, repetindo erros de outros analistas.

No caso da ANTT, vemos no Estudo Técnico n. 01 (2011), que enfatiza aplicação do CAPM ao cálculo de taxas de retorno de concessões ferroviárias, que a especificação do retorno justo sobre o capital próprio é idêntica à da ANEEL, acima discutida. As diferenças se verificam principalmente nos prazos pelos quais os valores médios dos vários componentes são calculados. Assim, por exemplo, a taxa de retorno livre de risco baseia-se em cotações de US Treasury Bonds de 30 anos, observadas mensalmente em um período de 15 anos; o prêmio por risco de mercado também se baseia nos retornos mensais do índice S\&P 500, em um período de 15 anos; o prêmio por risco país também usa o EMBI+ $\mathrm{BR}$, mas com valores médios calculados ao longo de 5 anos.

Ou seja, verifica-se mais uma vez o uso de prêmio por risco país, como nos laudos de avaliação de empresas, e sempre com médias históricas de retornos, em lugar de retornos implícitos em preços 
correntes de ativos financeiros e, portanto, representativos de condições correntes de mercado, ou seja, são constatados os mesmos erros conceituais da ANEEL.

Assim, tendo sido apresentado o levantamento da prática em duas áreas importantes de aplicação, destacam-se esses dois problemas sérios. Na próxima seção, é apresentada a metodologia para verificar se seria necessário adicionar um prêmio por risco país, usando-se o índice de mercado local, como seria “consistência conceitual”, conforme a ANEEL (Nota Técnica n. 75, 2013, fls. 5).

Um bom levantamento junto a usuários bem-informados do CAPM (ex-alunos do programa de MBA da University of Chicago), realizado por Keck et al. (1998), revelou diversas inconsistências, sendo a mais relevante, para este trabalho, aquela relacionada ao fato de que, embora 27 dos 118 respondentes declarassem que acreditavam em um CAPM com um único fator de risco, na verdade faziam seus cálculos de custo de capital com mais de um fator, e por isso foram chamados de CAPM Non-Purists pelos autores do levantamento. Além disso, 68 respondentes usavam modelos de mais de um fator, e os fatores adicionais de risco mais comumente citados eram: inflação, tributação, risco político, risco soberano e risco cambial.

Na opinião dos autores do levantamento, o comportamento geral observado era incompatível com a teoria do CAPM, mas compatível com a crença de que risco político e risco soberano eram variáveis de estado relevantes, embora eles (autores) se declarassem céticos a esse respeito. Em conclusão, afirmam que a prática é pouco científica a respeito (Keck et al., 1998, p. 91): "Our survey suggests that practitioners and experts alike adjust the discount rate for 'bogeys' that they perceive in foreign markets but are unable to quantify analytically."

Fica claro, portanto, que os fatores adicionais não são incluídos de maneira refletida ou com base teórica ou empírica sólida. Daí a importância de testá-los com uma metodologia apropriada.

\section{Teste da Relevância do Prêmio por Risco País}

Aplicou-se aqui a metodologia descrita em apêndice, usando dados de ações de 204 empresas diferentes, com os respectivos retornos mensais de janeiro de 2009 a dezembro de 2013 (60 meses). Foi exigido que as séries mensais fossem completas, e apenas uma classe de ação de cada empresa foi utilizada.

Para o retorno da carteira de mercado utilizou-se o Ibovespa, e o prêmio por risco país foi medido pelo blended spread da dívida brasileira, ou seja, do índice EMBI+ BR, como o empregado por várias consultorias em laudos de avaliação e agências regulatórias. Os dados estão disponíveis em Thomson Datastream. Tanto os retornos das ações individuais quanto o do Ibovespa foram medidos após a conversão dos seus níveis à taxa de câmbio entre reais e dólares norte-americanos.

Foi assim estimada a equação (9), embora nesse estudo o vetor $\mathrm{Z}$ represente apenas um fator de risco, além do risco da carteira de mercado, a saber, o risco país.

Resumindo, estimou-se inicialmente uma equação de regressão linear simples, na qual a variável dependente é a variação mensal do prêmio por risco país e a variável independente é o retorno mensal da carteira do Ibovespa.

Obtêm-se, assim, resíduos que são usados na estimação da equação (9). Assim, a variável Z representa o comportamento do risco país que não é explicado pelo Ibovespa e, portanto, independe do comportamento do próprio Ibovespa.

Em síntese, a relevância do risco país só existirá se o coeficiente $\gamma$ for significativamente diferente de zero, pois, se isso ocorrer, então os retornos observados das várias ações serão determinados pelo retorno da carteira de mercado e também pelo comportamento do risco país. 
Analisadas as 204 ações, porém, descobriu-se que em apenas 17 o resultado é significante no nível de 5\%. Isso permite concluir que, claramente, o risco país não é relevante, após ser levada em conta a sua relação com o Ibovespa. Em outras palavras, o comportamento do Ibovespa já é influenciado pelo comportamento do risco país e, uma vez montada uma equação para explicar retornos pela carteira de mercado local, é incorreto e desnecessário acrescentar um prêmio por risco país. E esse resultado era bastante previsível, porém, ao observarmos que, durante o período, a correlação entre retornos do Ibovespa e variações do blended spread da dívida brasileira atingiu o nível de -0,7491.

\section{Exemplo de Aplicação}

O que foi apresentado anteriormente neste estudo aponta dois problemas básicos com a utilização do CAPM para a estimação de custo de capital próprio, tal como é feita na prática generalizada. O primeiro problema é a utilização de taxas passadas para calcular tanto o retorno do ativo livre de risco quanto os prêmios por risco de mercado e país, quando todos esses componentes podem ser extraídos, direta ou indiretamente, de cotações correntes e bem mais representativas do que está ocorrendo naquele momento nos mercados correspondentes. O segundo, é a adição do prêmio por risco país. Bastando usar o prêmio por risco da carteira de mercado local, esse prêmio se tornaria irrelevante, porque já estaria refletido nas cotações das ações locais e, portanto, no prêmio por risco da carteira de mercado local.

Apresenta-se, a seguir, um conjunto de cálculos num caso real, para se indicar quão variável pode ser a estimativa obtida de custo de capital próprio. O caso diz respeito ao laudo de avaliação da Cia. Iguaçu de Café Solúvel, feito com data-base de setembro de 2008.

A empresa consultora que fez a avaliação obteve a seguinte estimativa, supondo fluxos de caixa em dólares norte-americanos:

- Taxa de retorno livre de risco, baseada na média de taxas do US Treasury Bond com prazo de 30 anos, no período de 1997 a 2007: 6,71\% ao ano.

- Prêmio por risco da carteira de mercado norte-americano, baseado na média do mesmo período e em relação ao US Treasury Bond de 30 anos: 2,68\% ao ano.

. Prêmio por risco país: 3,00\% ao ano, segundo Damodaran.

Portanto, o custo de capital próprio, para beta igual a um, seria de 12,39\% ao ano, como calculou a consultoria.

Entretanto, se fossem usadas cotações correntes de 30 de setembro de 2008, incluindo a estimação do prêmio por risco de mercado com a carteira local e sem a inclusão do prêmio por risco país, dada a redundância com o risco de mercado local, teríamos:

Taxa de retorno livre de risco, pelo yield to maturity de US Tresasury Bonds de prazo de 30 anos: $4,40 \%$ ao ano.

Prêmio por risco da carteira de mercado: $10,49 \%$ ao ano.

Portanto, o custo de capital próprio, supondo beta igual a um, seria estimado em 14,89\% ao ano. Ou seja, 250 pontos de base acima do que foi calculado no laudo de avaliação. Se tomássemos uma série de fluxos operacionais de caixa (EBITDA) por ação e em perpetuidade, de USD 2,1309, como no final de 2008, esses fluxos de caixa valeriam USD 17,20/ação, segundo o enfoque adotado pela consultoria. Da maneira proposta neste estudo, porém, o valor apropriado seria de USD 14,31/ação. Ou seja, um erro de precificação da ordem de aproximadamente $17 \%$. 


\section{Conclusão}

Os resultados obtidos na análise efetuada ao longo deste estudo indicam que, ao se utilizar como carteira de mercado o índice local de ações (Ibovespa), a inclusão ad hoc e separada de um prêmio por risco Brasil não só é irrelevante, como representaria dupla consideração desse risco na precificação de ações.

O mercado local já é suficientemente bem desenvolvido para que os preços correntes das ações incorporem informação a respeito de riscos relevantes, como o risco Brasil. A postura daí decorrente, por parte dos analistas e das agências regulatórias, envolveria não apenas substituir o uso comum de dados do mercado norte-americano, como levar apropriadamente em conta os dados do mercado local, especialmente quando o objetivo é precificar ativos locais.

Como limitação do presente trabalho, mas principalmente como possível extensão, fica a sugestão de que em outros trabalhos a mesma metodologia seja aplicada para se validar a utilização frequente de outros fatores de risco sistemático, dentre os quais se sobressai o fator tamanho. E, como sugestão para o aprimoramento tanto profissional quanto acadêmico do conhecimento de técnicas de avaliação de ativos, fica a de que haja um esforço de reflexão sobre o motivo pelo qual práticas que já foram demonstradas serem conceitualmente incorretas permanecem, por inércia, sendo repetidas em avaliações tão importantes para a economia brasileira. Esse esforço deve começar nas escolas, pelos professores de finanças, e espera-se que esse trabalho possa ser utilizado como subsídio para isto.

\section{Referências}

Carvalho, M. R. A., \& Sanvicente, A. Z. (2013). Determinants of the implied equity risk premium in Brazil [Working Paper]. Insper Instituto de Ensino e Pesquisa, São Paulo, SP, Brasil. Recuperado de http://www.insper.edu.br/wp-content/uploads/2013/02/ERP-vers\%C3\%A3o-jan-2013.docx

Comissão de Valores Mobiliários. (2008). Laudos e editais de OPAs registradas em 2008. Recuperado de http://sistemas.cvm.gov.br/?OfertasReg

Comissão de Valores Mobiliários. (2009). Laudos e editais de OPAs registradas em 2009. Recuperado de http://sistemas.cvm.gov.br/?OfertasReg

Comissão de Valores Mobiliários. (2010). Laudos e editais de OPAs registradas em 2010. Recuperado de http://sistemas.cvm.gov.br/?OfertasReg

Comissão de Valores Mobiliários. (2011). Laudos e editais de OPAs registradas em 2011. Recuperado de http://sistemas.cvm.gov.br/?OfertasReg

Comissão de Valores Mobiliários. (2012). Laudos e editais de OPAs registradas em 2012. Recuperado de http://sistemas.cvm.gov.br/?OfertasReg

Comissão de Valores Mobiliários. (2013). Laudos e editais de OPAs registradas em 2013. Recuperado de http://sistemas.cvm.gov.br/?OfertasReg

Deloitte Touche Tohmatsu Consultores Ltda. (2009). Laudo de avaliação: Companhia Maranhense de Refrigerantes. Central de Sistemas Comissão de Valores Mobiliários, Laudos e Editais de OPAs Registradas em 2010. Recuperado de http://sistemas.cvm.gov.br/?OfertasReg

Estudo Técnico $n^{\circ} 01$ de 26 de dezembro de 2011. (2011). Metodologia para apuração de estrutura e remuneração de capital. Brasília, DF: Agência Nacional de Transportes Terrestres. Recuperado 
de

http://appweb2.antt.gov.br/acpublicas/cpublica2011001/Anexo2_Estudo_Tecnico_WACC_e_BR.pdf

Hirashima \& Associados. (2008). Laudo de avaliação econômico-financeira para oferta pública de aquisição de ações preferenciais e ordinárias da Calçados Azaléia S.A. Central de Sistemas Comissão de Valores Mobiliários, Laudos e Editais de OPAs Registradas em 2008. Recuperado de http://sistemas.cvm.gov.br/?OfertasReg

Keck, T., Levengood, E., \& Longfield, A. (1998). Using discounted cash flow analysis in an international setting: a survey of issues in modeling the cost of capital. Journal of Applied Corporate Finance, 11(3), 82-99. doi: 10.1111/j.1745-6622.1998.tb00505.x

Koedijk, K. G., Kool, C. J. M., Schotman, P. C., \& Dijk, M. A. van (2002). The cost of capital in international financial markets: local or global? Journal of International Money and Finance, 21(6), 905-929.

Lintner, J. (1965). Security prices, risk, and maximal gains from diversification. Journal of Finance, 20(4), 587-615.

Mossin, J. (1966). Equilibrium in a capital asset market. Econometrica, 34(4), 768-783.

Nota Técnica $n^{\circ} 75$ de 22 de março de 2013. (2013). Metodologia e critérios gerais para definição do custo de capital a ser utilizado no cálculo da remuneração das instalações de transmissão de energia elétrica. Brasília, DF: Agência Nacional de Energia Elétrica. Recuperado de http://www.aneel.gov.br/aplicacoes/audiencia/arquivo/2013/031/documento/nota_tecnica_n\%C 2\%BA_75_sre-aneel.pdf

Sercu, P. (1980). A generalization of the international asset pricing model. Revue de l'Association Française de Finance, 1(1), 91-135.

Sharpe, W. F. (1964). Capital asset prices: a theory of market equilibrium under conditions of risk. Journal of Finance, 19(3), 425-442.

Solnik, B. (1983). International arbitrage pricing theory. Journal of Finance, 38(2), 449-457. doi: 10.1111/j.1540-6261.1983.tb02251.x

Stewart, G. B. (1991). The quest for value. New York: HarperCollins Publishers.

\section{Dados do Autor}

Antonio Zoratto Sanvicente

Rua Itapeva, 474, 01332-000, São Paulo, SP, Brasil. E-mail: antonio.sanvicente@ fgv.br 


\section{APÊNDICE}

Segundo Koedijk, Kool, Schotman e Dijk (2002), doravante referidos como KKSvD, quando se deseja escolher o modelo apropriado para o custo de capital próprio sob a hipótese de que os mercados de capitais são integrados, há duas alternativas possíveis:

1. O International CAPM (ICAPM) multifatorial de Solnik (1983) e Sercu (1980), em que a carteira de mercado é um índice global e, além disso, o retorno exigido também poderia envolver um prêmio de risco cambial.

2. O CAPM local, em que um único fator de risco está envolvido, pois o risco do índice local já refletiria a sua exposição ao mercado internacional e ao risco cambial, além de outros riscos, como o risco país [nossa ênfase].

Segundo esses autores, os dois modelos de precificação de ativos resultariam no mesmo custo de capital próprio, se a carteira de mercado local contivesse toda informação relevante para a avaliação de ativos domésticos em termos internacionais. maneira:

Na primeira alternativa descrita acima, o modelo proposto poderia ser especificado da seguinte

$$
\mathrm{E}\left[\mathrm{R}_{\mathrm{i}}-\mathrm{r}_{0}\right]=\mathrm{E}\left[\mathrm{R}_{\mathrm{G}}-\mathrm{r}_{0}\right] \mathrm{d}_{\mathrm{i} 1}+\mathrm{E}\left[\mathrm{S}+\mathrm{r}-1 \mathrm{r}_{0}\right] \mathrm{d}_{\mathrm{i} 2}
$$

Onde $\mathrm{R}_{\mathrm{i}}$ e $\mathrm{R}_{\mathrm{G}}$ são os retornos do i-ésimo ativo e da carteira de mercado global, respectivamente, ambos medidos na moeda de referência, ou seja, a moeda nacional 0 do i-ésimo ativo. $\mathrm{S}$ corresponde ao vetor de variações relativas (taxas de retorno) das taxas de câmbio para outros países $\mathrm{i}=1,2, \ldots, \mathrm{N}$ em relação ao país 0 . $\mathrm{O}$ vetor $\mathrm{r}$ contém os retornos nominais dos ativos livres de risco nos $\mathrm{N}$ países, sendo $\mathrm{r}_{0}$ a taxa livre de risco no país 0 , e 1 é o vetor unitário. ${ }^{(1)}$

Por sua vez, $\mathrm{d}_{\mathrm{i} 1}$ e $\mathrm{d}_{\mathrm{i} 2}$ são os betas do i-ésimo ativo em relação ao índice de mercado global e às $\mathrm{N}$ taxas de câmbio, ou seja, são os coeficientes de regressão na seguinte equação:

$$
\mathrm{R}_{\mathrm{i}}=\alpha_{1 \mathrm{i}}+\mathrm{R}_{\mathrm{G}} \mathrm{d}_{\mathrm{i} 1}+\mathrm{S}^{\prime} \mathrm{d}_{\mathrm{i} 2}+\mathrm{u}_{\mathrm{i}}=\alpha_{1 \mathrm{i}}+\mathrm{Z}^{\prime} \mathrm{d}_{\mathrm{i}}+\mathrm{u}_{\mathrm{i}}
$$

Onde $Z^{\prime}=\left(R_{\mathrm{G}} \mathrm{S}^{\prime}\right), \alpha_{1 \mathrm{i}}=\mathrm{r}_{0}\left(1-\mathrm{d}_{\mathrm{i} 1}\right)+\left(\mathrm{r}-1 \mathrm{r}_{0}\right){ }^{\prime} \mathrm{d}_{\mathrm{i} 2}$ é uma constante, e $\mathrm{u}_{\mathrm{i}}$ é o risco específico ortogonal a Z.

No segundo modelo, a especificação seria:

$$
\mathrm{E}\left[\mathrm{R}_{\mathrm{i}}-\mathrm{r}_{0}\right]=\mathrm{E}\left[\mathrm{R}_{\mathrm{L}}-\mathrm{r}_{0}\right] \mathrm{b}_{\mathrm{i}}
$$

Onde $\mathrm{R}_{\mathrm{L}}$ é o retorno do índice de mercado local denominado na moeda 0 . $\mathrm{O}$ beta do ativo i no CAPM local corresponde ao coeficiente de regressão na seguinte equação:

$$
\mathrm{R}_{\mathrm{i}}=\alpha_{2 \mathrm{i}}+\mathrm{R}_{\mathrm{L}} \mathrm{b}_{\mathrm{i}}+\mathrm{e}_{\mathrm{i}}
$$

Como a equação (2) é válida para um ativo individual, também é válida para a carteira de mercado local de qualquer país. Portanto, aplicando a equação (3) a $\mathrm{R}_{\mathrm{L}}$, obtemos:

$$
\mathrm{R}_{\mathrm{L}}=\alpha_{\mathrm{L}}+\mathrm{Z}^{\prime} \mathrm{d}_{\mathrm{L}}+\mathrm{u}_{\mathrm{L}}
$$

Inserindo (5) em (4), obtemos: 


$$
\mathrm{R}_{\mathrm{i}}=\alpha_{3 \mathrm{i}}+\mathrm{Z}^{\prime} \mathrm{d}_{\mathrm{L}} \mathrm{b}_{\mathrm{i}}+\mathrm{u}_{\mathrm{L}} \mathrm{b}_{\mathrm{i}}+\mathrm{e}_{\mathrm{i}}
$$

Onde $\alpha_{3 i}=b_{i} \alpha_{L}$. As equações (2) e (6) levam à mesma decomposição entre risco não diversificável e risco específico quando o risco específico do mercado local, $\mathrm{e}_{\mathrm{i}}$ na equação (4), é ortogonal a Z. Assim, o termo composto de risco específico $u_{L} b_{i}+e_{i}$ na equação (6) é ortogonal a $Z$, e as equações (2) e (6) são idênticas. Sendo assim, então os parâmetros das duas equações são idênticos, o que equivale a dizer que:

$$
\mathrm{d}_{\mathrm{i}}=\mathrm{d}_{\mathrm{L}} \mathrm{b}_{\mathrm{i}}
$$

Interpretando-se a equação (7) como uma restrição e, supondo-se que ela seja válida, então o uso do primeiro modelo (CAPM multifatorial) ou do segundo modelo (CAPM local) não produzirá erros de precificação, e ambas as alternativas levarão à estimação do mesmo custo de capital próprio.

Uma das maneiras de testar essa restrição consiste em adicionar os instrumentos Z, que podem incluir prêmios por diversos tipos de risco que o analista queira considerar, à regressão para o CAPM local, ou seja, usar a equação (8) com a hipótese nula $\mathrm{H}_{0}$ : $\delta_{\mathrm{i}}=0$ :

$$
\mathrm{R}_{\mathrm{i}}=\alpha_{4 \mathrm{i}}+\mathrm{R}_{\mathrm{L}} \mathrm{b}_{\mathrm{i}}+\mathrm{Z}^{\prime} \delta_{\mathrm{i}}+\mathrm{v}_{\mathrm{i}}
$$

Se a hipótese nula não for rejeitada, então o risco que poderá ser diversificado no mercado local também poderá ser diversificado no mercado global, e vice-versa. Desse modo, a carteira de mercado local conterá toda a informação relevante para fins de avaliação de ativos, mesmo do ponto de vista de um investidor internacional. Caso contrário, o modelo precisaria incluir prêmios por riscos adicionais não contemplados na versão local do CAPM.

Estimando a equação (8) por mínimos quadrados ordinários, KKSvD obtém os seguintes resultados principais, usando dados de 3293 empresas de nove países com mercados de capitais desenvolvidos, e empregando retornos mensais cobrindo o período de 1980 a $1999^{(2)}$.

1. O CAPM local produz estimativas significativamente diferentes de custo de capital próprio para apenas 5\% das empresas da amostra, o que quer dizer que o erro de precificação, quando se usa a versão local do modelo, em lugar da versão internacional, é pequeno.

2. Os autores atribuem a proximidade entre a precificação local e a precificação global à forte influência de fatores locais sobre os retornos de ações individuais, talvez por causa da ausência de integração efetiva entre os vários mercados ${ }^{(3)}$.

Para a obtenção dos resultados acima relatados, utilizou-se a metodologia KKSvD, ou seja, foi testada a significância do prêmio por risco país em adição ao risco da carteira de mercado local. Em outras palavras, a questão básica é determinar se é necessário incluir um prêmio por risco país quando se usa o índice local como proxy da carteira de mercado.

Dada a elevada correlação negativa entre variações mensais do índice de mercado local e o spread de risco país $(-0,7491)$, uma estimação mais eficiente da equação (8) por mínimos quadrados ordinários exigiria a sua reparametrização, conforme proposto por KKSvD. O procedimento consiste em utilizar a equação (9):

$$
\mathrm{R}_{\mathrm{i}}=\alpha_{4 \mathrm{i}}+\mathrm{R}_{\mathrm{L}} \mathrm{b}_{\mathrm{i}}+\mathrm{Z}^{* \prime} \gamma_{\mathrm{i}}+\mathrm{v}_{\mathrm{i}}
$$

Onde $\mathrm{Z}^{*}$ é um vetor contendo valores ortogonalizados da proxy de risco país, e $\mathrm{R}_{\mathrm{L}}=$ retorno mensal do índice de mercado local. A variável que representa o prêmio por risco país é medida pela variação mensal entre a diferença de taxas de títulos da dívida brasileira e um índice de notas do Tesouro dos Estados Unidos com prazo de 10 anos $^{(4)}$. 
Os valores ortogonalizados correspondem aos resíduos obtidos com a estimação de uma equação de regressão linear simples, na qual a variável dependente é Z, que pode representar qualquer fator de risco a ser considerado, ou mesmo algum vetor de fatores de risco. A variável independente, por sua vez, é a taxa de retorno do índice de mercado local.

Portanto, este resíduo corresponde à informação sobre o comportamento do prêmio por risco país, não refletida no comportamento do índice de mercado local, e o teste assim envolve a significância de $\mathrm{Z}^{*}$, medida por meio do parâmetro $\gamma_{\mathrm{i}}$.

\section{Notas}

\footnotetext{
${ }^{1}$ Segundo KKSvD, os prêmios por risco de variação de taxas de câmbio são incluídos em vista de evidências abundantes de violação da condição de paridade do poder de compra das moedas.

${ }^{2}$ Os retornos utilizados são os dos índices global e nacionais calculados por Morgan Stanley Capital International (MSCI) de maneira a permitir uma comparação mais direta de resultados. Os países cobertos por KKSvD foram: Alemanha, Austrália, Canadá, Estados Unidos, França, Holanda, Japão, Reino Unido e Suíça.

${ }^{3}$ Ressalte-se, como está evidente na nota anterior, que os mercados analisados foram os de países cujos mercados de capitais são mais fortemente integrados. Os autores dizem ainda que os resultados obtidos fortalecem o chamado home bias puzzle, ou seja, a preferência dos administradores de investimentos por títulos negociados no mercado local de origem, apesar de haver benefícios substanciais disponíveis caso suas carteiras sejam mais diversificadas em termos internacionais.

${ }^{4}$ Foi utilizado o índice calculado pela empresa JP Morgan Chase, conforme disponível no banco de dados Datastream.
} 